Note

\section{Volatile Components Identified in the Acidic Fractions of Wines from Koshu and Zenkoji Grapes}

\section{Jun-ichi Shimizu and Masazumi Watanabe \\ Central Research Laboratories of Kikkoman Corp., 399-Noda, Noda-shi, Chiba 278, Japan}

Received May 19, 1981

In a previous paper, ${ }^{1)}$ about 40 components were identified in the volatile fractions from Koshu and Zenkoji wines respectively by a combined gas chromatographmass spectrometric analysis (GC-MS). Furthermore, to determine the essential flavor components of wine, ${ }^{2)}$ flavor concentrates of the both wines were systematically separated into four fractions (acidic, phenolic, basic and neutral) ${ }^{3)}$ and each fraction was served to a sensory test. The results indicated that wine-like flavor existed in the neutral fraction, of which the main components were alcohols and esters. ${ }^{4,5}$ ) The four fractions each had a characteristic flavor. ${ }^{6)}$ Especially, the acidic fraction did not have a wine-like, alcoholic or esteric flavor, but possesed fatty acidic and strong pricked odors. However, this fraction was deemed to be important in causing a synergistic increase of wine flavor based on the sensory test of four fractions, the reconstitution of wine flavor by mixing the four fractions and the additive effect of each fraction to the original wine.

This paper deals with the identification of volatile components in the acidic fractions separated from Koshu and Zenkoji wines by a gas chromatograph-mass spectrometer, with findings of 9 new compounds as wine volatile components and with the differences of volatiles between the two wines.

The sample wines used in the present experiments and

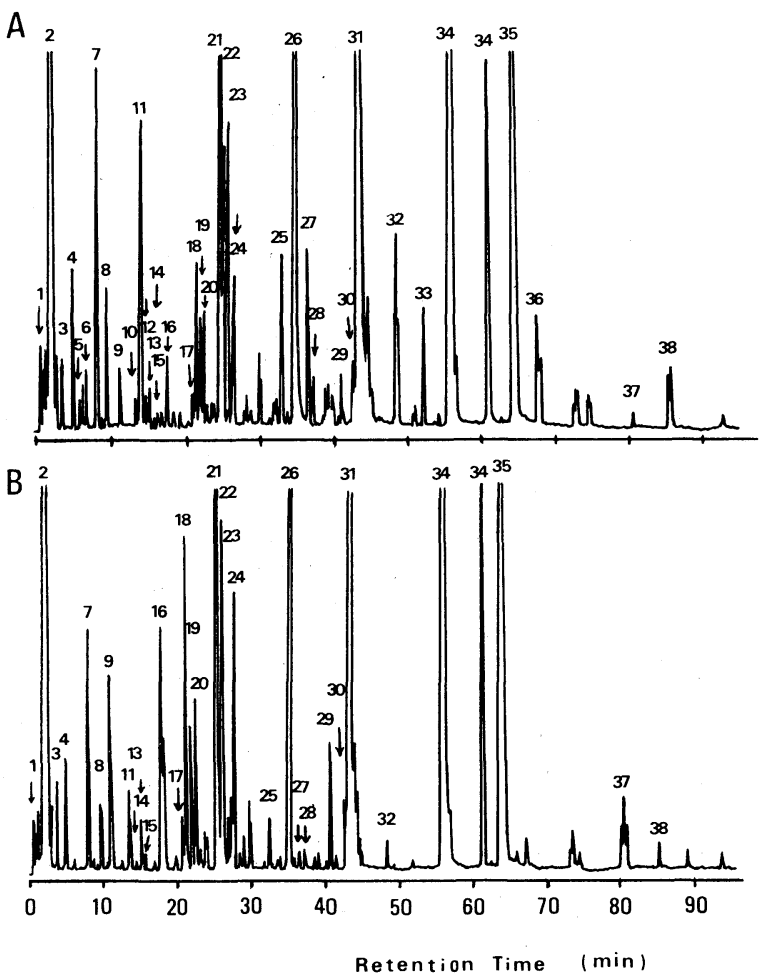

FIG. 1. Gas Chromatograms of Volatile Concentrates of the Acidic Fractions from Koshu and Zenkoji Wines.

A, Koshu wine; B, Zenkoji wine. Operating conditions were as follows. Instrument, Hitachi 063-RMU-7M (GC-MS); column, FFAP, $0.28 \mathrm{~mm}$ (i.d.) $\times 30 \mathrm{~m}$, glass capillary; oven temp., $50 \sim 170^{\circ} \mathrm{C}\left(3^{\circ} \mathrm{C} / \mathrm{min}\right)$; carrier gas, $\mathrm{He}, 0.2 \mathrm{~kg} / \mathrm{cm}^{2}(0.7 \mathrm{ml} / \mathrm{min})$; split ratio, $100: 1$; ionization electron energy, $70 \mathrm{eV}$; ion source temp., $240^{\circ} \mathrm{C}$. Peak numbers correspond to those in Table I. Peak Nos. 1 and 2 show carbon dioxide and dichloromethane, respectively. 
the procedures for preparation of the acidic fraction from the total volatile concentrate of both wines are described in the previous report. ${ }^{1)}$ The volatile concentrate $(50 \mathrm{ml})$, obtained by direct extraction of each wine (10 liters) with purified dichloromethane, was extracted twice with $50 \mathrm{ml}$ of $3 \% \mathrm{Na}_{2} \mathrm{CO}_{3}$ solution. After the combined aqueous layer was adjusted to $\mathrm{pH} 1.5$ with conc. $\mathrm{HCl}$, it was again extracted twice with each $100 \mathrm{ml}$ of purified dichloro-

Table I. Identified Volatile Components in the Acidic Fractions of Koshu and Zenkoji Wines

\begin{tabular}{|c|c|c|c|c|}
\hline Compounds & Peak Nos. & $\begin{array}{l}\text { Methods for } \\
\text { identification }^{a}\end{array}$ & $\begin{array}{l}\text { Found in the } \\
\text { neutral fraction }\end{array}$ & Ref. \\
\hline \multicolumn{5}{|l|}{ Acids } \\
\hline Acetic acid & 16 & MS, GC & & \\
\hline Propionic acid & 17 & MS, GC & & \\
\hline 2-Methylpropionic acid & 19 & MS, GC & & \\
\hline Butyric acid & 21 & MS, GC & & \\
\hline 3-Methylbutyric acid & 23 & MS, GC & & \\
\hline Pentanoic acid & 24 & MS, GC & & \\
\hline Hexanoic acid & 26 & MS, GC & & \\
\hline Heptanoic acid & 28 & MS, GC & & \\
\hline Octanoic acid & 31 & MS, GC & & \\
\hline Decanoic acid & 34 & MS, GC & & \\
\hline Monoethyl succinate & 35 & MS, GC, SP & & \\
\hline Dodecanoic acid & 37 & MS, GC & & \\
\hline \multicolumn{5}{|l|}{ Alcohols } \\
\hline 1-Propanol & 3 & MS, GC & + & 1) \\
\hline 2-Methyl-1-propanol & 4 & MS, GC & + & 1) \\
\hline 1-Butanol & 6 & MS, GC & + & 1) \\
\hline 3-Methyl-1-butanol & 7 & MS, GC & + & 1) \\
\hline 2-Methyl-2-butanol & 10 & MS & & \\
\hline 1-Hexanol & 13 & MS, GC & + & 1) \\
\hline 3-Ethoxy-1-propanol & 14 & MS, GC & + & 1) \\
\hline trans-2-Hexenol & 15 & MS, GC & & \\
\hline 2,3-Butanediol (levo) & 18 & MS, GC & & \\
\hline 2,3-Butanediol (meso) & 20 & MS, GC & & \\
\hline 2-Phenylethanol & 27 & MS, GC & + & 1) \\
\hline \multicolumn{5}{|l|}{ Esters } \\
\hline Ethyl butyrate & 3 & $\mathrm{MS}, \mathrm{GC}, \mathrm{SP}$ & + & 1) \\
\hline 3-Methylbutyl acetate & 5 & MS, GC, SP & + & 1) \\
\hline Ethyl hexanoate & 8 & MS, GC, SP & + & 1) \\
\hline Ethyl lactate & 11 & MS, GC, SP & & \\
\hline 2-Methylpropyl hexanoate & 12 & MS, GC, SP & & \\
\hline \multicolumn{5}{|l|}{ Lectones } \\
\hline$\gamma$-Butyrolactone & 22 & MS, GC & & \\
\hline 5-Hydroxypentanoic acid lactone & 25 & MS & & \\
\hline$\gamma$-Heptalactone & 30 & MS & & \\
\hline 6-Ethyl- $\delta$-pentalactone & 36 & MS & & \\
\hline \multicolumn{5}{|l|}{ Carbonyls } \\
\hline Acetoin & 9 & MS, GC & + & 1) \\
\hline 2-Methyl-3-heptanone & 30 & MS & & \\
\hline Vanillin & 38 & MS, GC & & \\
\hline \multicolumn{5}{|l|}{ Phenol } \\
\hline 2-Methoxy-5-vinylphenol & 32 & MS & & \\
\hline \multicolumn{5}{|l|}{ Miscellaneous } \\
\hline 2-n-Butyltetrahydrofuran & 29 & MS & & \\
\hline 2,4-di-tert-Butylthiophene & 33 & MS & & \\
\hline
\end{tabular}

a MS, gas chromatography-mass spectrometry; GC, retention time of authentic samples by gas chromatography; SP, gas chromatographic determination after saponification by the method previously reported. ${ }^{1)}$ Peak numbers correspond to those in both A and B of Fig. 1. 
Table II. Mass Spectral Data of New Components Found in Koshu OR ZENKoJI Wine Volatile

\begin{tabular}{|c|c|c|c|}
\hline Peak No. & Compounds & $\mathbf{M}^{+}$ & $m / z$ (Relative intensity) \\
\hline 10 & 2-Methyl-2-butanol & $(88)^{a}$ & $59(100), 73(57), 45(40), 55(30), 43(25), 31(24)$ \\
\hline 14 & 3-Ethoxy-1-propanol & $(104)^{a}$ & $31(100), 59(67), 58(45), 45(40), 29(30), 57(27)$ \\
\hline 25 & $\begin{array}{l}\text { 5-Hydroxypentanoic } \\
\text { acid lactone }\end{array}$ & 100 & $42(100), 41(71), 56(45), 55(25), 100(27), 28(27)$ \\
\hline 29 & $\begin{array}{l}\text { 2-n-Butyltetra- } \\
\text { hydrofuran }\end{array}$ & 128 & $71(100), 43(37), 41(19), 27(19), 29(11), 39(9)$ \\
\hline 30 & $\gamma$-Heptalactone & 128 & 85 (100), 29 (29), $56(15), 57(14), 41(10), 43(10)$ \\
\hline 30 & 2-Methyl-3-heptanone & 128 & $57(100), 43(88), 85(69), 41(65), 27(55), 29(47)$ \\
\hline 32 & $\begin{array}{l}\text { 2-Methoxy-5-vinyl- } \\
\text { phenol }\end{array}$ & 150 & $150(100), 135(66), 44(27), 107(23), 77(17), 89(7)$ \\
\hline 33 & $\begin{array}{l}\text { 2,4-di-tert-butyl- } \\
\text { thiophene }\end{array}$ & 196 & $181(100), 196(21), 41(17), 182(13), 57(9), 39(7)$ \\
\hline 36 & 6-Ethyl- $\delta$-pentalactone & 128 & $42(100), 99(83), 27(70), 55(57), 41(55), 71(53)$ \\
\hline
\end{tabular}

a Molecular weight.

methane. Washing with distilled water, back extraction and dehydration of the extract were carefully and adequately carried out. The extract was finally concentrated to about $2 \mathrm{ml}$ by a rotary evaporator at room temperature in vacuo.

The volumetric ratios of the acidic fractions thus obtained to the total volatile concentrates from Koshu and Zenkoji wines were about $26 \%$ and $29 \%$, respectively.

Figure 1 shows gas chromatograms of the volatile concentrates of the acidic fractions from Koshu and Zenkoji wines by a capillary column. Both patterns are very similar with only slight differences. The results of the sensory test of the two concentrates are also much the same.

As shown in Table I, 12 compounds were respectively identified by GC-MS as acidic volatile components in the acidic fractions of Koshu and Zenkoji wines. All these compounds were further confirmed by GC against authentic samples. The constitution ratios of the acidic volatile components to the total compounds found in the fractions of Koshu and Zenkoji wines were approximately $61 \%$ and $66 \%$, respectively. The acidic compounds identified were all detected in both Koshu and Zenkoji wines although their amounts were slightly different. These components. have already been reported by $\mathrm{Webb}^{4)}$ and Schreier ${ }^{5)}$ and their presence in wines was known irrespective of the grape varieties used in the wine making.

In spite of careful operations during fractionation, many kinds of alcohols and esters contaminated the acidic fractions of both the wines (Table I). However, their amounts were very small in comparison with those found in the neutral fraction. ${ }^{1)}$ Twenty-six compounds in Koshu wine and 20 compounds in Zenkoji wine were found, respectively. They were almost neutral volatile components. Some differences of the volatile constituents between both the wines were recognized (Fig. 1). Six compounds (peak Nos. 5, 6, 10, 12, 33 and 36) found in Koshu wine could not be detected in Zenkoji wine. Two compounds (peak Nos. 5 and 6) in these compounds have previously been reported in Zenkoji wine. ${ }^{1)}$ The other four components found in Koshu wine were trace and three out of these four components were newly found as wine volatiles. These components seem to have been formed by yeast fermentation, because they have not been previously reported in $\mathrm{Koshu}^{7)}$ and some other grape musts. ${ }^{4,5)}$

Table II shows the mass spectral data of nine compounds first found as wine volatile components in Koshu and Zenkoji wines. They were all found in Koshu wine, but three of these compounds could not be detected in Zenkoji wine. To make clear the influence of these trace compounds on the wine flavor, fractionation of the peak composition corresponding to these compounds by preparative GC, sniffing and the additive effect of these components to the wine flavor concentrate were all tentatively investigated. However, the contribution of these components to the wine flavor could not be clarified, because their amounts were trace and, furthermore, their threshold values were not ascertained.

Acknowledgments. The authors wish to express their gratitude to Dr. N. Iguchi and Dr. F. Yoshida of Kikkoman Corp., for their support and encouragement. Thanks are also due to Dr. S. Nasuno for help in the preparation and critical reading of this manuscript.

\section{REFERENCES}

1) J. Shimizu and M. Watanabe, Agric. Biol. Chem., 45, 2797 (1981).

2) C. J. Van Wyk, R. E. Kepner and A. D. Webb, J. Food Sci., 32, 669 (1967).

3) H. Inoue, H. Morita and M. Ukai, J. Ferment. 
Technol., 45, 305 (1967).

4) A. D. Webb, The Proceedings of the 5th Biennial International Codata Conference, Univ. of Colorado, June 28, 1976, p. 101.

5) P. Schreier, CRC Critical Reviews in Food Science and Nutrition, November, 1979, 59.

6) K. Ueno, N. Matsumoto, K. Takeuchi and H. Togawa, J. Brewing Soc. Jpn., 75, 492 (1980).

7) J. Shimizu and M. Watanabe, J. Jpn. Soc. Hort. Sci., 50, 400 (1981). 